\title{
Survival in renal cortical necrosis due to snake bite
}

\author{
S. RAMACHANDRAN \\ M.D., M.R.C.P., M.R.C.P.E.
}

\author{
M. V. F. Perera \\ D.C.P., M.R.C.P.E.
}

Colombo North General Hospital, Ragama, Sri-Lanka

\begin{abstract}
Summary
A case of acute renal cortical necrosis following snake bite is reported. The case illustrates that survival is possible in renal cortical necrosis following snake bite and that even in the presence of anuria or prolonged oliguria active treatment of the acute renal failure following snake bite is indicated.

\section{Introduction}

Acute renal failure is not uncommon following bites by species of snakes belonging to the groups elapids, vipers and sea snakes. Bilateral renal calcification observed in a patient who had anuria following snake bite indicated that bilateral renal cortical necrosis was the pathological lesion causing the anuria (Oram et al., 1963) and recently renal cortical
\end{abstract}

necrosis was seen at post mortem in a case of viper bite (Varagunam and Panabokke, 1970).

This paper reports survival in a patient who had acute renal failure due to cortical necrosis following snake bite.

\section{Case report}

M.S., male, 50 years old, was admitted in September 1972 with a history of having been bitten by a snake 3 days previously. The snake was not killed and hence not available for identification. He had not passed urine since the time of the bite and complained of loin pain and hiccough. On examination there was no abnormality in his mental state, nervous system, respiratory or cardio-vascularo system. There were no haemorrhages in skin and the

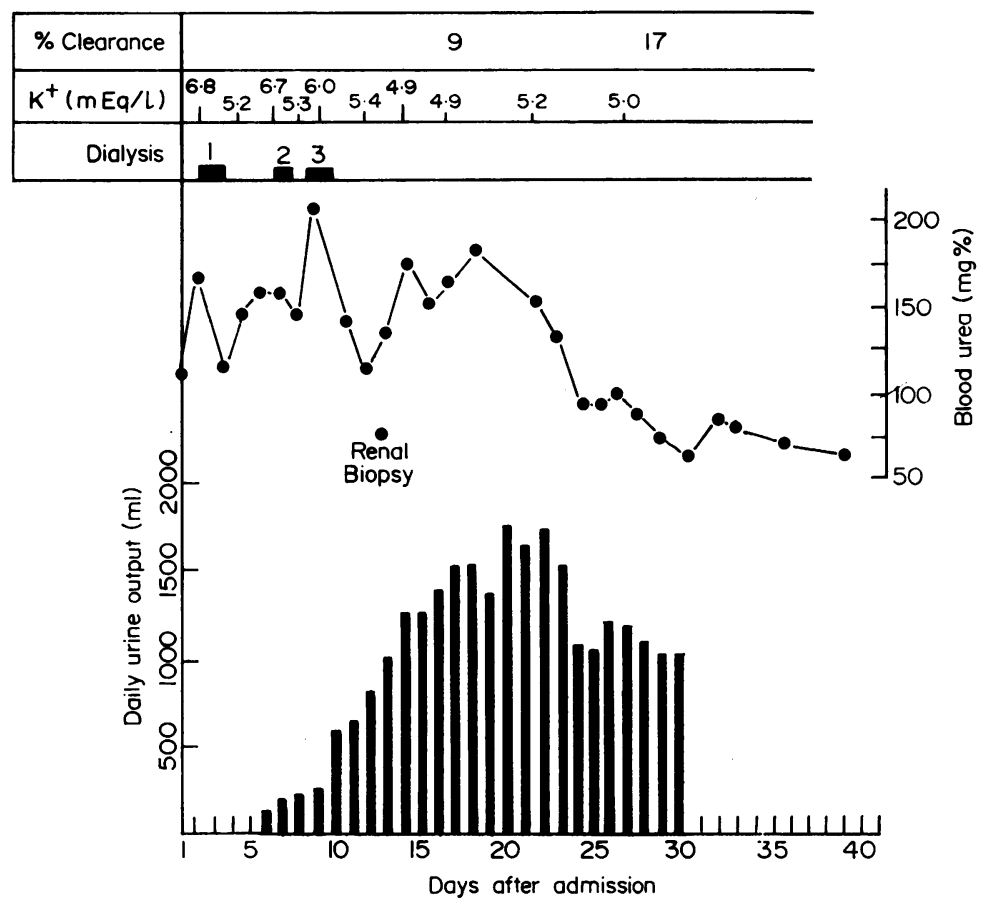

Fig. 1. Shows the course of the clinical illness. 


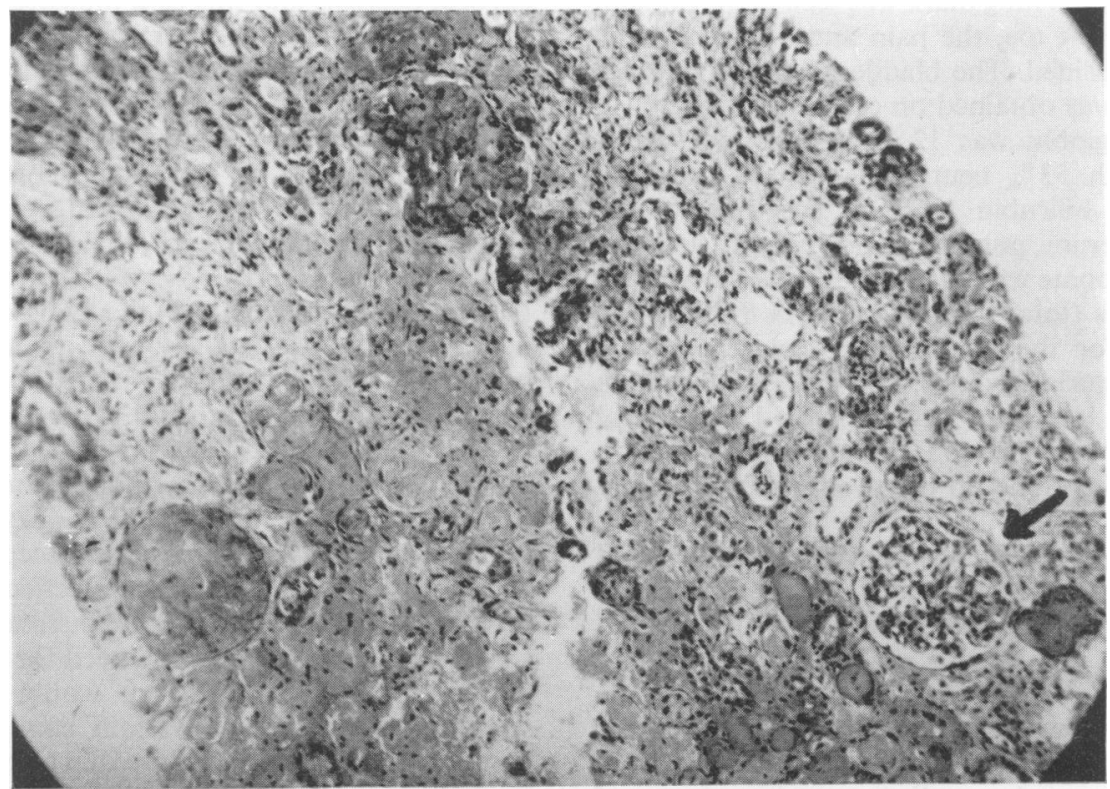

Fig. 2. Histology of the kidney showing acute renal cortical necrosis with a completely destroyed glomerulus, a partially necrosed one and a normal glomerulus (arrow) $\times 350$.

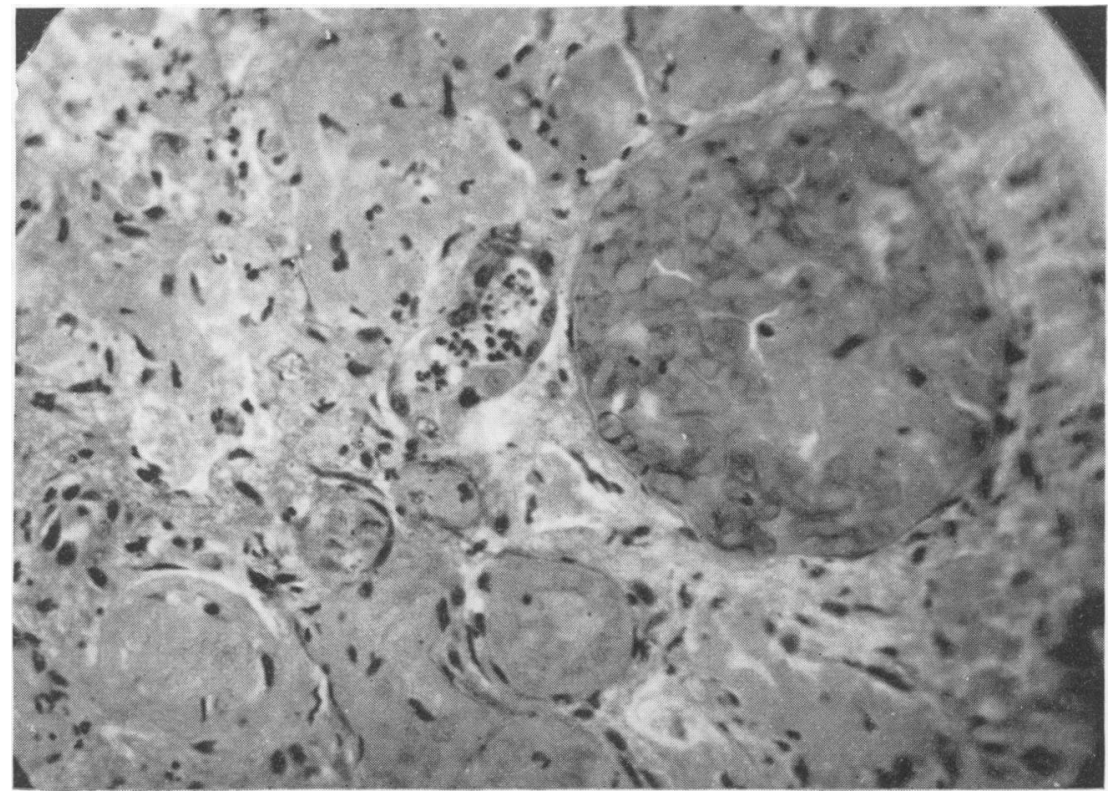

Fig. 3. Shows a necrosed glomerulus with tubular necrosis, $\times 500$. 
mucous membranes. The blood pressure was $120 / 80$. One healed fang mark was seen in the dorsum of the second left toe, the pain and swelling at the site having subsided. The bladder was not palpable and no urine was obtained on catheterization.

The haemoglobin was $12 \mathrm{~g} / \%$, leucocyte count $7200 / \mathrm{mm}^{3}$ with $53 \%$ neutrophils, blood urea 110 $\mathrm{mg} / \%$, serum bilirubin $1.1 \mathrm{mg} / \%$, serum sodium $146 \mathrm{mEq} / \mathrm{l}$, serum potassium $6.8 \mathrm{mEq} / \mathrm{l}$, and the plasma bicarbonate was $16 \mathrm{mEq} / \mathrm{l}$. He was anuric for the first 5 days (total period of anuria 8 days) and was oliguric for the next 4 days (total period of anuria and oliguria 12 days). The urine output, urea and potassium levels are shown in Fig. 1. Peritoneal dialysis was performed on three occasions and a renal biopsy was done on the twelfth day. He went home on the fortieth day with a blood urea of 70 $\mathrm{mg} / \%$ and a percentage clearance of 17 . He could now concentrate his urine to a specific gravity of 1015 and there was no radiological evidence of renal calcinosis.

The renal biopsy showed scattered areas of acute cortical necrosis where both glomeruli and tubules were completely necrotic. In some partially surviving areas there were glomeruli in varying stages of necrosis and some normal glomeruli. The tubules in these areas showed varying degrees of tubular degeneration. There was interstitial oedema and cellular infiltration (Figs. 2 and 3).

Eight months after discharge from hospital he was clinically well with a blood urea of $76 \mathrm{mg} / \%$. There was no renal calcification.

\section{Discussion}

This case shows definite evidence of acute renal cortical necrosis following snake bite and also indicates the value of renal biopsy both in detecting the nature and extent of the renal lesions in patients with acute renal failure (Gormsen, Iversen and Raaschou, 1956). The acute cortical necrosis was wide spread and scattered and the presence of normal glomeruli probably accounted for the recovery of adequate renal function for survival (Lloyd-Thomas, Balm and Key, 1962). Survival has been described in only a very small proportion of patients with acute cortical necrosis and this case indicates that survival is also possible in the cortical necrosis following snake bite (Walls, Schorr and Kerr, 1968).

The vasculotoxic properties of snake venom probably caused the prolonged ischaemia necessary for the development of the renal cortical necrosis (Papper, 1971). Some striking features were: (1) the absence of shock, collapse, haemolysis and local tissue loss which could have initiated or potentiated the renal ischaemia, and (2) the complete absence of neurological and haemorrhagic manifestations in spite of the renal damage. These features suggest that either the concentration of venom could have been optimal in the kidneys by virtue of its abundant blood supply per unit volume (Varagunam and Panabokke, 1970), or that the kidney in some individuals may have an increased susceptibility to the vasculotoxic and nephrotoxic effects of snake venom. Anuria occurring immediately after the snake bite while stressing the need for early administration of antivenom serum would also lead to speculation whether antivenom can prevent renal damage. In acute renal failure due to cortical necrosis following snake bite the possibility of survival stresses the need for prolonged management of renal failure with dialysis treatment.

\section{References}

Gormsen, H., Iversen, P. \& RaAschou, F. (1956) Kidney biopsy in acute anuria. American Journal of Medicine, 19, 209.

Lloyd-Thomas, H.G., Balm, R.H. \& Key, J.J. (1962) Tramline calcification in renal cortical necrosis. British Medical Journal, 1, 909.

Oram, S., Ross, G., Pell, L. \& Winteler, J. (1963) Renal cortical calcification after snake bite. British Medical Journal, 1, 1647.

Papper, S. (1971) Clinical Nephrology. Little, Brown and Co., Boston.

Varagunam, T. \& Panabokke, R.G. (1970) Bilateral cortical necrosis of the kidney following snake bite. Postgraduate Medical Journal, 46, 449.

Walls, J., Schorr, W.J. \& Kerr, D.N.S. (1968) Prolonged oliguria with survival in acute bilateral cortical necrosis. British Medical Journal, 4, 220. 